University of Nebraska - Lincoln

DigitalCommons@University of Nebraska - Lincoln

Public Health Resources

Public Health Resources

2002

Centers for Disease Control and Prevention 2000 Growth Charts for the United States: Improvements to the 1977 National Center for Health Statistics Version

Cynthia L. Ogden

National Center for Health Statistics, cao9@cdc.gov

Robert J. Kuczmarski

National Center for Health Statistics

Katherine M. Flegal

National Center for Health Statistics

Zuguo Mei

National Center for Chronic Disease Prevention and Health Promotion, Centers for Disease Control and Prevention

Shumei Guo

Wright State University

See next page for additional authors

Follow this and additional works at: http://digitalcommons.unl.edu/publichealthresources

Ogden, Cynthia L.; Kuczmarski, Robert J.; Flegal, Katherine M.; Mei, Zuguo; Guo, Shumei; Wei, Rong; Grummer-Strawn, Laurence M.; Curtin, Lester R.; Roche, Alex F.; and Johnson, Clifford L., "Centers for Disease Control and Prevention 2000 Growth Charts for the United States: Improvements to the 1977 National Center for Health Statistics Version" (2002). Public Health Resources. 455.

http://digitalcommons.unl.edu/publichealthresources/455

This Article is brought to you for free and open access by the Public Health Resources at DigitalCommons@University of Nebraska - Lincoln. It has been accepted for inclusion in Public Health Resources by an authorized administrator of DigitalCommons@University of Nebraska - Lincoln. 


\section{Authors}

Cynthia L. Ogden, Robert J. Kuczmarski, Katherine M. Flegal, Zuguo Mei, Shumei Guo, Rong Wei, Laurence M. Grummer-Strawn, Lester R. Curtin, Alex F. Roche, and Clifford L. Johnson 


\title{
Centers for Disease Control and Prevention 2000 Growth Charts for the United States: Improvements to the 1977 National Center for Health Statistics Version
}

\author{
Cynthia L. Ogden, PhD*; Robert J. Kuczmarski, DrPH*; Katherine M. Flegal, PhD*; Zuguo Mei, MD‡; \\ Shumei Guo, PhD§; Rong Wei, PhD*; Laurence M. Grummer-Strawn, PhD ; Lester R. Curtin, PhD*; \\ Alex F. Roche, MD, PhD, ScD\&; and Clifford L. Johnson, $\mathrm{MSPH}^{*}$
}

\begin{abstract}
Objective. To present a clinical version of the 2000 Centers for Disease Control and Prevention (CDC) growth charts and to compare them with the previous version, the 1977 National Center for Health Statistics (NCHS) growth charts.

Methods. The 2000 CDC percentile curves were developed in 2 stages. In the first stage, the empirical percentiles were smoothed by a variety of parametric and nonparametric procedures. To obtain corresponding percentiles and $z$ scores, we approximated the smoothed percentiles using a modified LMS estimation procedure in the second stage. The charts include of a set of curves for infants, birth to 36 months of age, and a set for children and adolescents, 2 to 20 years of age.

Results. The charts represent a cross-section of children who live in the United States; breastfed infants are represented on the basis of their distribution in the US population. The 2000 CDC growth charts more closely match the national distribution of birth weights than did the 1977 NCHS growth charts, and the disjunction between weight-for-length and weight-for-stature or length-for-age and stature-for-age found in the 1977 charts has been corrected. Moreover, the 2000 CDC growth charts can be used to obtain both percentiles and $z$ scores. Finally, body mass index-for-age charts are available for children and adolescents 2 to 20 years of age.
\end{abstract}

Conclusion. The $2000 \mathrm{CDC}$ growth charts are recommended for use in the United States. Pediatric clinics should make the transition from the 1977 NCHS to the 2000 CDC charts for routine monitoring of growth in infants, children, and adolescents. Pediatrics 2002;109:4560; growth charts, stature, length, weight, body mass index, head circumference, NHANES, preschool-age children, disjunction.

ABBREVIATIONS. NCHS, National Center for Health Statistics; CDC, Centers for Disease Control and Prevention; WHO, World Health Organization; BMI, body mass index; NHANES, National Health and Nutrition Examination Survey.

From the *National Center for Health Statistics, Hyattsville, Maryland; $\ddagger$ National Center for Chronic Disease Prevention and Health Promotion Centers for Disease Control and Prevention, Atlanta, Georgia; and §Wright State University, Kettering, Ohio.

Received for publication Apr 18, 2001; accepted Jul 24, 2001.

Reprint requests to (C.L.O.) Division of Health Examination Statistics, National Center for Health Statistics/Centers for Disease Control and Prevention, 6525 Belcrest Rd, Rm 900, Hyattsville, MD 20782. E-mail: cao9@cdc.gov PEDIATRICS (ISSN 0031 4005). Copyright $\odot 2002$ by the American Academy of Pediatrics.
T The 1977 National Center for Health Statistics (NCHS) growth charts for infants and older children ${ }^{1}$ have been used widely in pediatric practice to assess the nutritional and health status of children and to monitor individual growth. In 1978, the Centers for Disease Control and Prevention (CDC) produced a normalized version of the 1977 NCHS percentiles. ${ }^{2,3}$ The World Health Organization (WHO) subsequently adopted these normalized curves as an international reference (CDC/WHO growth charts). ${ }^{4-6}$ Researchers have used these 1978 charts to calculate prevalence estimates and $z$ scores, compare populations, monitor trends, evaluate interventions, and define nutritional outcomes.

Concerns about the 1977 NCHS charts along with the availability of recent, comprehensive data, and improved statistical smoothing procedures, led to a revision of the charts and the release in May 2000 of the CDC growth charts for the United States. ${ }^{7}$ The main concerns about the 1977 NCHS charts centered on the use of Fels Research Institute ${ }^{8}$ data for the infant charts. ${ }^{9-11}$ Although not ideal, the Fels data were considered the best available data at the time and some of the limitations of incorporating them were clearly stated with the initial release. ${ }^{12}$ Nevertheless, 4 main issues related to using the Fels data led to criticisms of the 1977 growth charts. First, the data were not representative of the entire country; data from the Fels Institute were derived from white, middle-class infants living in southwestern Ohio between 1929 and 1975. Second, the infants in the Fels sample, similar to what was happening nationally during those years, were primarily formula fed. Third, birth weights in the Fels sample did not match the national distribution of birth weights. Fourth, differences between recumbent length in the Fels data set and stature in the national data used for the older child charts were too large, leading to a disjunction between the infant and older child growth curves between 24 and 36 months of age. ${ }^{2,3,9}$

Two other concerns about the 1977 NCHS growth charts also have been raised. First, the percentiles from the normalized version were not identical to the original 1977 NCHS percentiles. Second, the weightfor-stature charts ended at 10 or 11 years of age, making it impossible to evaluate weight adjusted for stature during adolescence.

The objective of this article is to present a clinical 
version of the $2000 \mathrm{CDC}$ growth charts containing 2 charts per page with data entry boxes and to compare the $2000 \mathrm{CDC}$ growth charts with the previous 1977 NCHS version.

\section{METHODS}

The 2000 CDC growth charts consist of a set of curves for infants, birth to 36 months of age, and a set for children and adolescents, 2 to 20 years of age. The infant growth charts consist of curves for weight-for-age, recumbent length-for-age, head circumference-for-age, and weight-for-recumbent length. The growth charts for children and adolescents include weight-forage, stature-for-age, and body mass index (BMI)-for-age. In addition, weight-for-stature charts were created for children between 77 and $121 \mathrm{~cm}$ in stature that are applicable primarily to children 2 to 5 years of age. ${ }^{7}$

National data collected in a series of 5 surveys between 1963 and 1994 were used to develop the 2000 CDC growth charts. ${ }^{7}$ The most recent was the NCHS/CDC Third National Health and Nutrition Examination Survey (NHANES III, 1988-1994). This survey was designed as a stratified, multistage probability sample based on the selection of counties, blocks, households, and persons within households. ${ }^{13}$ Preschool-age children were oversampled for the specific purpose of revising the 1977 NCHS growth charts. Similar to the previous health examination surveys, NHANES III consisted of a home interview and a standardized physical examination conducted in a mobile examination center. The physical examination included measurements of recumbent length, stature, weight, and head circumference. Head circumference and recumbent length were measured in children younger than 4 years, and stature was measured in children 2 years and older. Infants wore diapers, and children wore paper examination gowns and foam slippers.

In the infant charts, additional data were added at birth and during the first few months of life where national data were not available. These data sources included national birth certificate data for birth weight, birth lengths recorded in Missouri and Wisconsin, head circumference at birth from the Fels Research Institute, and length data from a subset of CDC's Pediatric Nutrition Surveillance System between 0.5 and 4.5 months of age.

Two substantial data exclusions were made before specific charts were created. First, all very low birth weight infants $(<1500$ g) were excluded from the infant growth charts. These infants have substantially different growth patterns than normal birth weight infants, and specialized growth charts for infants with birth weight $<1500 \mathrm{~g}$ are available. ${ }^{14-18}$ Second, all charts with weight and BMI exclude data from NHANES III for children ages 6 years and older. This exclusion was made because of the higher prevalence of overweight in this sample as compared with data from previous surveys. ${ }^{19}$ NHANES III had an unduly high influence on the curves compared with the other surveys. The NHANES III data alone shifted the upper percentiles of the weight and BMI curves, resulting in higher values for the 85th and 95th percentiles. Because the 85th percentile of BMI has been recommended as a cutoff to identify children and adolescents who are at risk for becoming overweight, ${ }^{20,21}$ the inclusion of NHANES III would lead to misclassification of overweight children as not overweight.

The smoothed percentile curves were developed in 2 stages. In the first stage, selected weighted empirical percentiles (3rd, 5th, 10th, 25th, 50th, 75th, 90th, 95th, and 97th) for specific age groups were smoothed with a variety of parametric and nonparametric procedures. The 85th percentile was also smoothed in the BMIfor-age charts. In the second stage, normalized growth curves were constructed to approximate the statistically smoothed empirical percentiles. These normalized curves were calculated using a modified LMS estimation procedure. The modified LMS procedure applies the LMS technique to smoothed curves as compared with the original LMS procedure, which is applied directly to the data points. Three parameters are estimated in this technique, L (the skewness parameter in the Box-Cox transformation), M (the median), and S (the generalized coefficient of variation). Then, using the equations below, a specific percentile or $z$ score $(Z)$ can be obtained:

$$
X=M(1+L S Z)^{1 / L} \text { or } Z=\left\{\left[(X / M)^{* *} L\right]-1\right\} / L S L \neq 0
$$

where $X$ is the physical measurement (eg, weight, length, head circumference, stature, or calculated BMI value) and $\mathrm{L}, \mathrm{M}$, and $\mathrm{S}$ are the values from the appropriate table corresponding to the age in months (or length/stature) of the child. The percentile corresponding to the obtained $z$ score is given in a normal distribution table (eg, $\mathrm{Z}=0$ corresponds to the 50 th percentile and $\mathrm{z}=-1.645$ corresponds to the 5 th percentile). A detailed description of the original LMS procedure ${ }^{22,23}$ and the data and methods used to develop the 2000 CDC growth curves are available. ${ }^{7,24}$

Clinical versions of the 2000 CDC growth charts are presented in Figs 1 to 10. They include boxes for data entry and are scaled to metric units. Length-for-age and weight-for-age percentiles are displayed in Figs 1 and 2 for infant boys and girls; head circumference-for-age and weight-for-length percentiles for infant boys and girls are displayed in Figs 3 and 4 . Figures 5 and 6 contain stature-for-age and weight-for-age percentiles for boys and girls ages 2 to 20 years. Figures 7 and 8 show BMI-for-age for boys and girls with the formula for calculating BMI included in the data entry box. Finally, Figs 9 and 10 contain weight-for-stature percentiles for boys and girls with statures between 77 and $121 \mathrm{~cm}$. These charts are available on the Internet (http:/ /www.cdc.gov/ growthcharts).

\section{RESULTS}

For demonstrating how some of the concerns about the 1977 NCHS growth charts were addressed in the revision, the 1977 NCHS and normalized 1978 $\mathrm{CDC} / \mathrm{WHO}$ growth charts based on the NCHS charts were compared with the 2000 CDC growth charts. Specific issues regarding the distribution of birth weights and the disjunction between length and stature were evaluated using data from the national distribution of birth weights and NHANES III.

The analytic data set from NHANES III included measurements of 1115 children between 24 and 35.9 months of age. Of the 12812 -year-old children examined in NHANES III, 155 were excluded because of missing values for stature, length, or weight. Eleven children were excluded because their stature and length measurements differed by $\geq 5 \mathrm{~cm}$. In the analyses of the weight-for-length and weight-forstature curves, another 504 children were excluded because their values fell outside the stature range of the 1977 NCHS growth charts.

SAS (SAS Institute, Cary, NC) and SUDAAN (Research Triangle Institute, Research Triangle Park, NC) were used to analyze the NHANES III data. All analyses included sample weights that account for the unequal probabilities of selection and nonresponse in the examination component of NHANES III. For accounting for the complex sample design, SUDAAN was used to calculate sampling errors.

\section{Representativeness}

Unlike the 1977 NCHS growth charts, the 2000 CDC growth charts for infants birth to 36 months are representative of a cross-section of children living in the United States between 1971 and 1994. Slightly more than $14 \%$ of the children included in the 2000 CDC growth charts database are black, which approximately represents the proportion of the 1980 US population of this age who were black. ${ }^{25}$ This reflects that the charts were created from nationally representative samples of infants, children, and adolescents, supplemented with data from additional sources, primarily at birth, where national survey data were absent. 


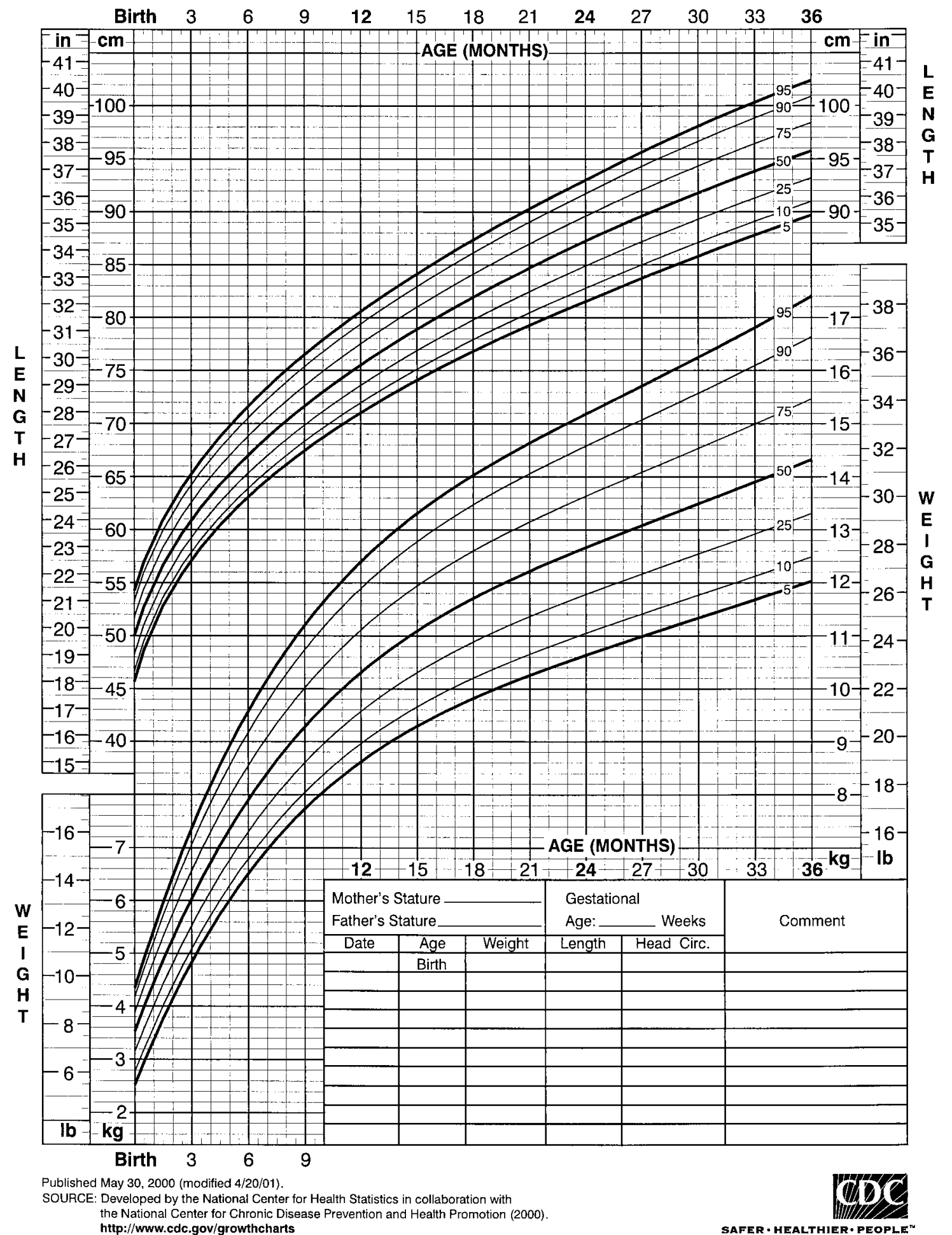

Fig 1. 2000 CDC growth charts for the United States, length-for-age and weight-for-age percentiles, birth to 36 months, boys.

\section{Infant Feeding}

Breastfed infants are included in the 2000 CDC growth charts proportional to their distribution in the US population during the past 30 years. During the past 2 decades, approximately half of US infants reportedly were breastfed; and among infants born from 1972 to 1994, approximately one-third were breastfed for at least 3 months. ${ }^{26}$ In NHANES II and III, approximately $50 \%$ of infants were ever breastfed and approximately $29 \%$ were still breastfed at 3 months. Data on breastfeeding were not available for NHANES I. 
Birth to 36 months: Girls

NAME

Length-for-age and Weight-for-age percentiles

RECORD \#

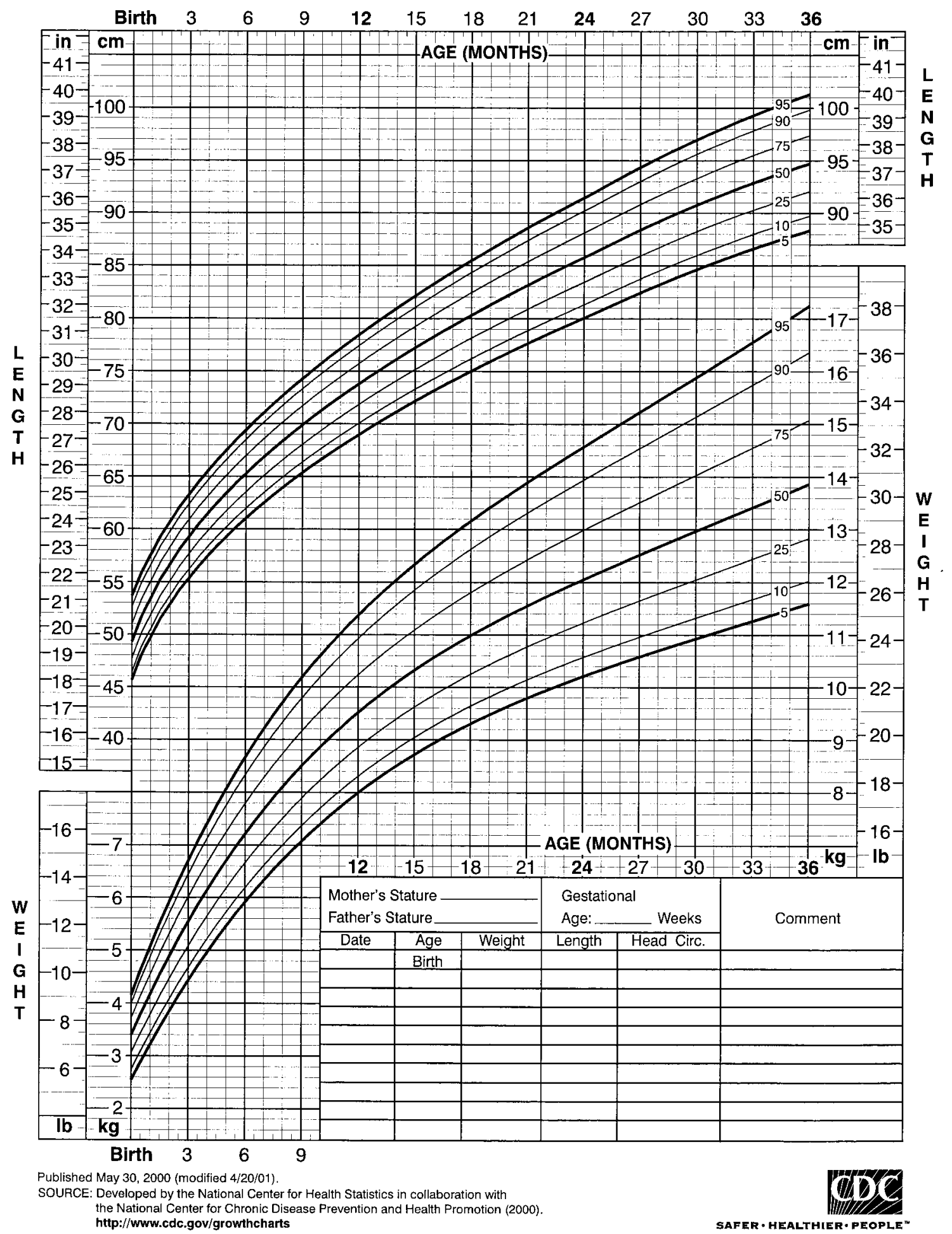

Fig 2. 2000 CDC growth charts for the United States, length-for-age and weight-for-age percentiles, birth to 36 months, girls.

\section{Birth Weights}

The 2000 CDC growth charts more closely match the national distribution of birth weights than did the 1977 NCHS growth charts. Figures 11 and 12 show the differences between specific percentile values of the national distribution of birth weights in 1977 and the percentile values at birth from the 1977
NCHS growth charts and, similarly, the differences between the birth weight percentiles in 1998 and in the 2000 CDC growth charts for boys and girls. The 1998 national distribution of birth weights excludes very low birth weight infants $(<1500 \mathrm{~g})$ to be consistent with the exclusion made in the 2000 CDC growth charts. Birth weights represented in the 1977 
Birth to 36 months: Boys

Head circumference-for-age and

Weight-for-length percentiles

NAME

RECORD \#

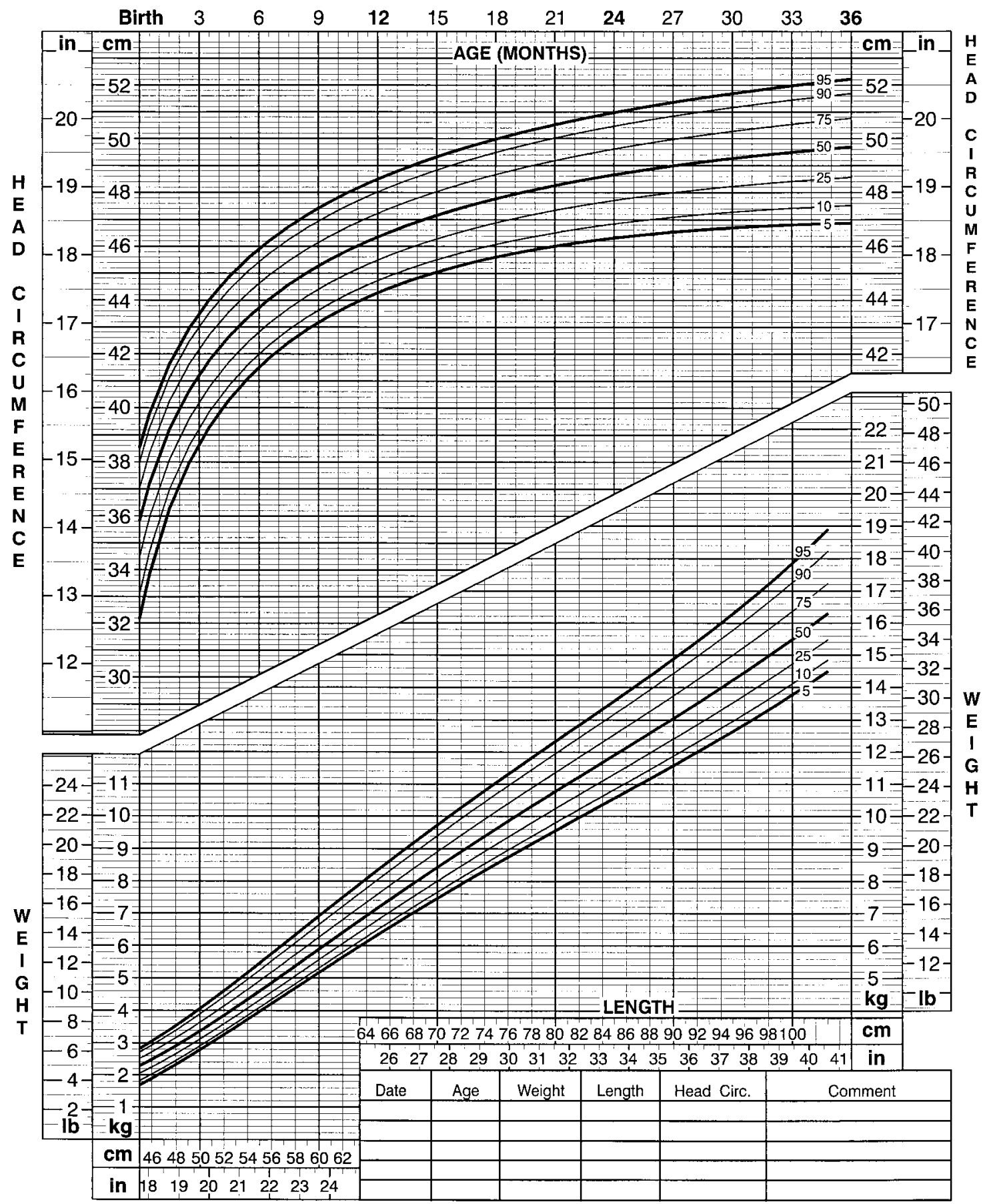

Published May 30, 2000 (modified 10/16/00)

SOURCE: Developed by the National Center for Health Statistics in collaboration with the National Center for Chronic Disease Prevention and Health Promotion (2000).
http://www.cdc.gov/growthcharts

tore

Fig 3. $2000 \mathrm{CDC}$ growth charts for the United States, head circumference-for-age and weight-for-length percentiles, birth to $36 \mathrm{months}$, boys.

NCHS growth charts were lower than the national birth weight distribution by $>100 \mathrm{~g}$ at the 75 th, 90 th, and 95th percentiles for both boys and girls. Although not shown, the differences between the birth points on the normalized CDC/WHO growth charts and the national distribution in 1977 are generally greater than the differences between the 1977 NCHS growth charts and the 1977 national distribution. Compared with the differences in 1977, the differences between the national distribution in 1998 and 
Birth to 36 months: Girls

Head circumference-for-age and

Weight-for-length percentiles

NAME

RECORD \#

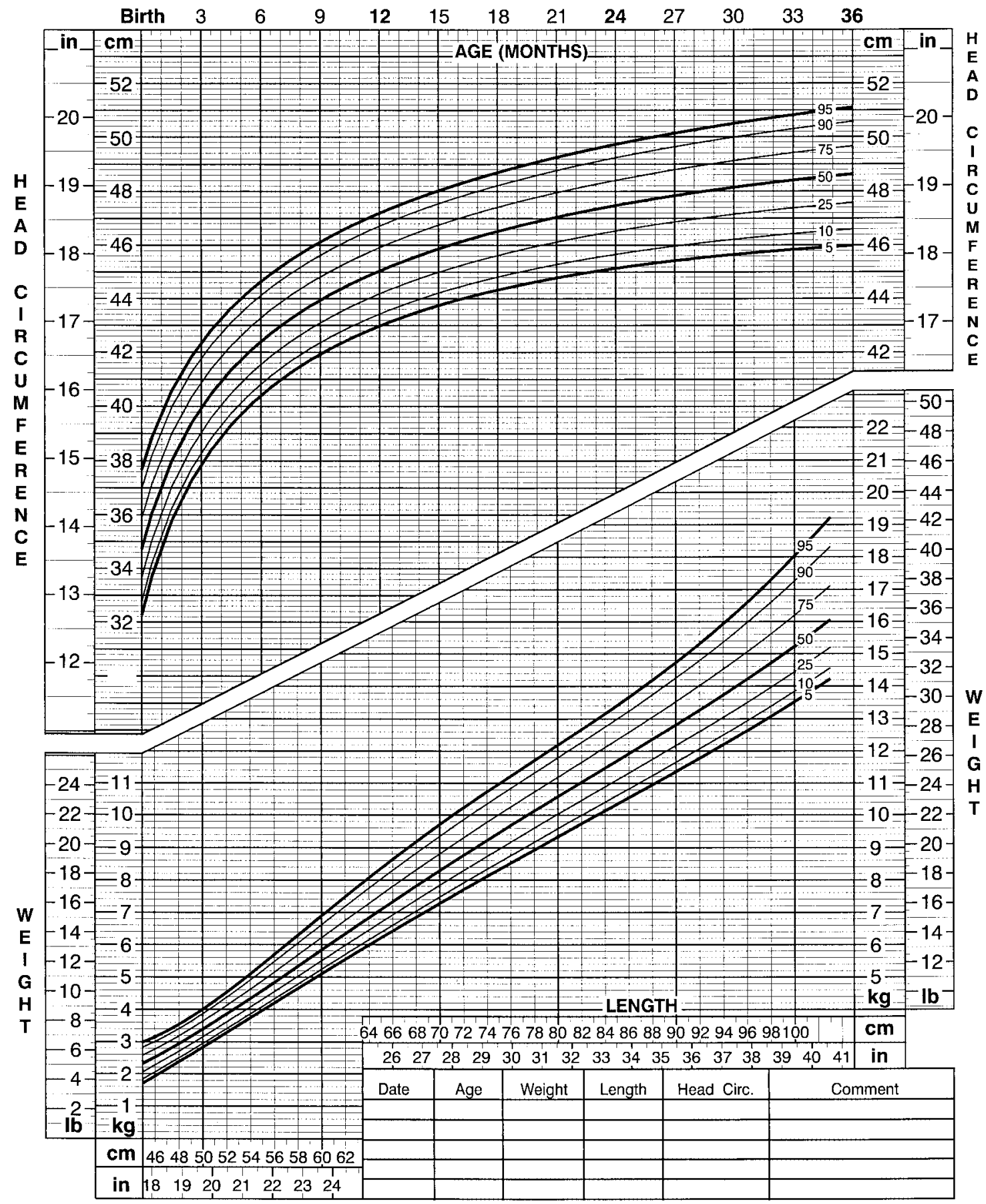

Published May 30, 2000 (modified 10/16/00)

SOURCE: Developed by the National Center for Health Statistics in collaboration with

the National Center for Chronic Disease Prevention and Health Promotion (2000)

100

http://www.cdc.gov/growthcharts

SAFER • HEALTHIER P PEOPLE

Fig 4. 2000 CDC growth charts for the United States, head circumference-for-age and weight-for-length percentiles, birth to 36 months, girls.

the 2000 CDC growth charts are generally smaller, except for the lower percentiles of girls, and more consistent. The birth weights in the 2000 CDC growth charts all are higher than the values in the
1998 national distribution. It should be noted that 1998 natality data were not used in smoothing the 2000 growth charts. Natality data from 1968 to 1980 and 1985 to 1994 were included in the construction of 
2 to 20 years: Boys

Stature-for-age and Weight-for-age percentiles

NAME

$\begin{array}{lllllllll}12 & 13 & 14 & 15 & 16 & 17 & 18 & 19 & 20\end{array}$

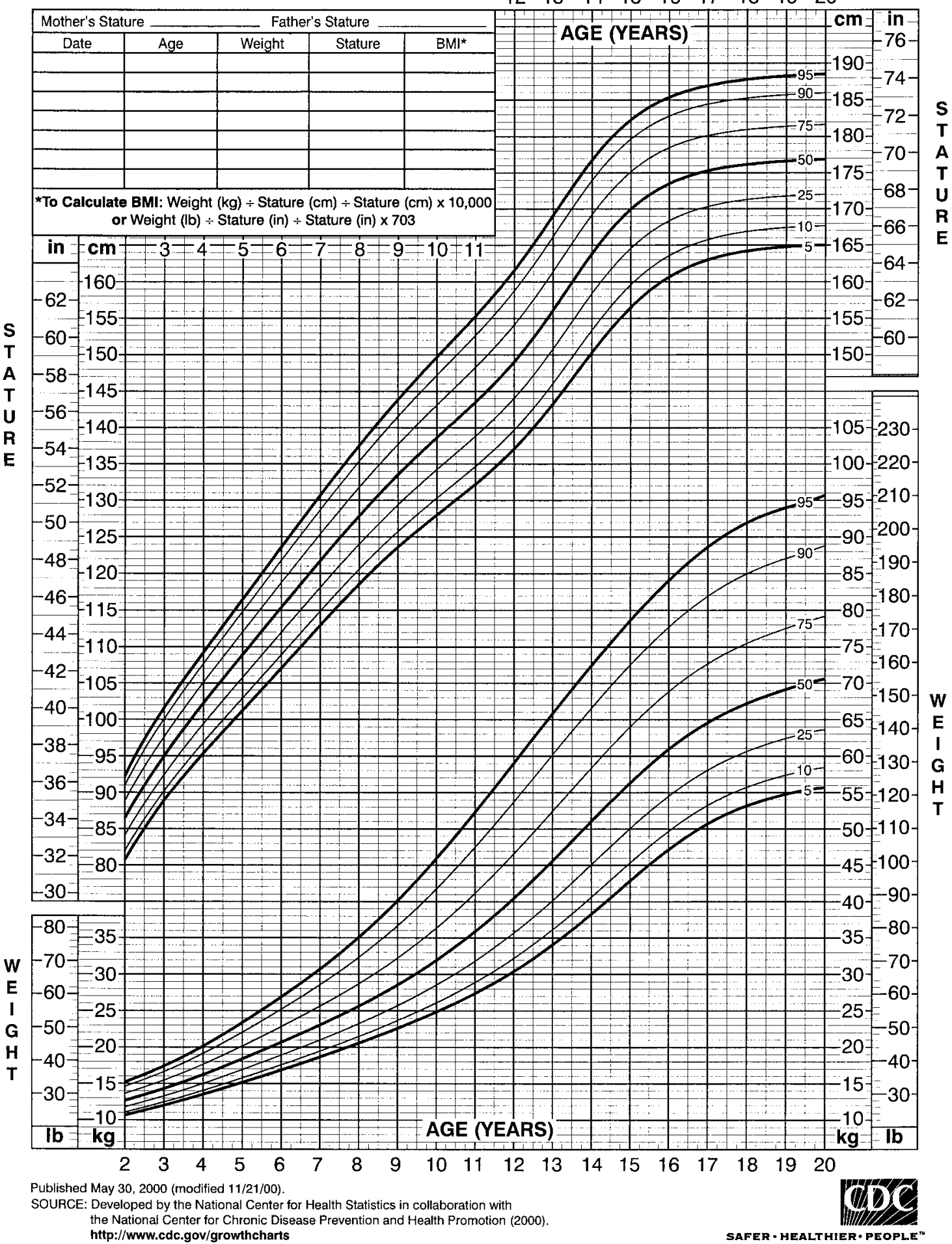

Fig 5. 2000 CDC growth charts for the United States, stature-for-age and weight-for-age percentiles, 2 to 20 years, boys.

the 2000 CDC growth charts because these years correspond to the years in which the infants in the national surveys were born.

\section{Disjunction}

In the 1977 versions of the growth charts, there was a larger-than-expected disjunction between length and stature. A child's measured length is generally greater than his or her stature; however, a child should fall at the same percentile for length as for stature. This was not true in the 1977 NCHS growth charts because there was an inconsistent relationship between the length and stature percentiles for both weight-for-length and weight-for-stature 


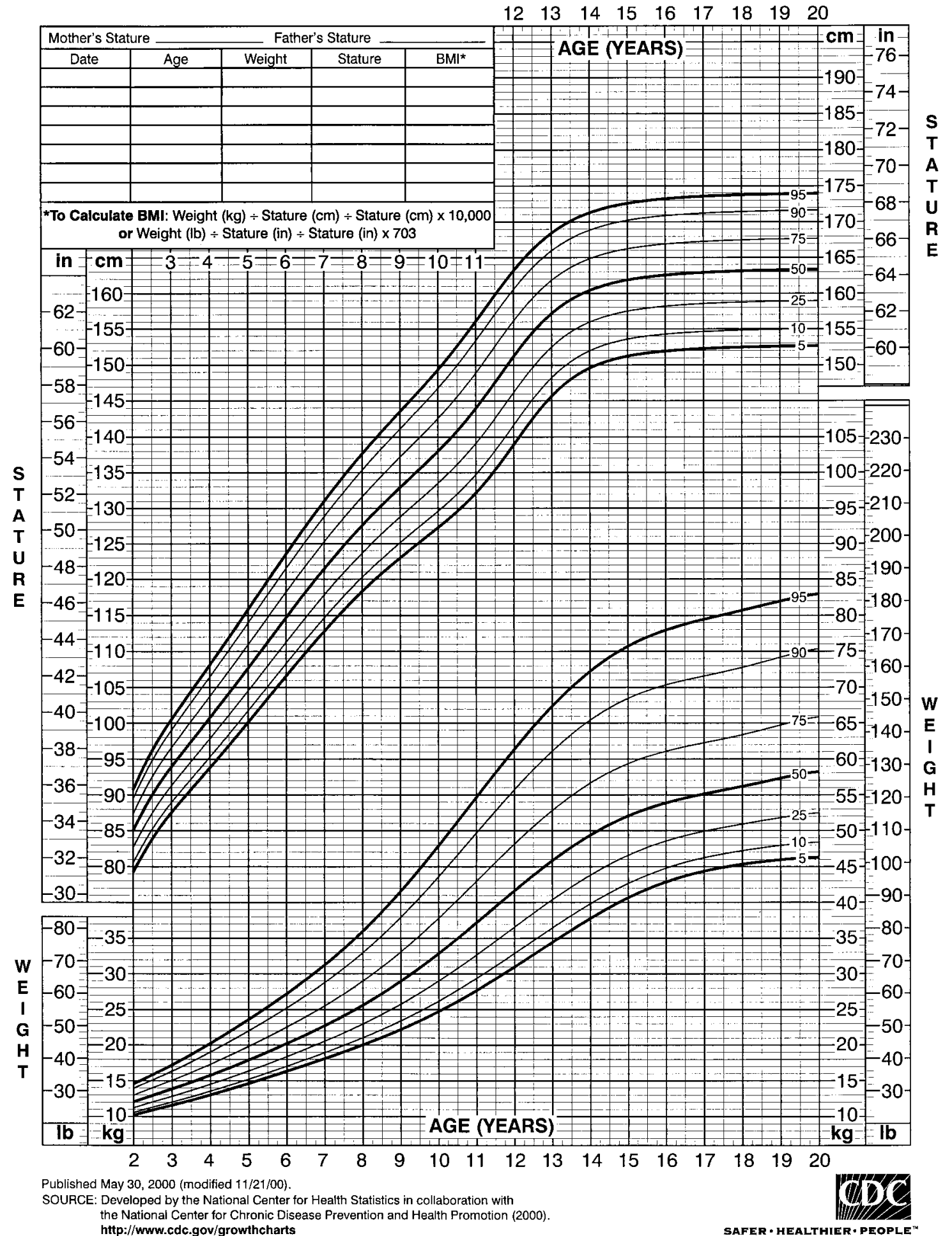

Fig 6. $2000 \mathrm{CDC}$ growth charts for the United States, stature-for-age and weight-for-age percentiles, 2 to 20 years, girls.

and for length-for-age and stature-for-age (Figs 13 and 14). The differences between the length and stature curves were inconsistent by age, percentile, or length values. Figure 13 shows the 5th, 50th, and 95th percentiles of the 1977 NCHS and 2000 CDC weightfor-length and weight-for-stature curves for girls 75 to $110 \mathrm{~cm}$ in length or stature. Figure 14 shows the same percentiles for the length-for-age and staturefor-age curves for girls ages 24 to 36 months. These figures demonstrate the disjunctions in the 1977 NCHS charts and a consistent $0.8-\mathrm{cm}$ parallel difference in the 2000 CDC charts based on the calculated mean difference between length and stature in children 24 to 36 months of age in NHANES II and III. 


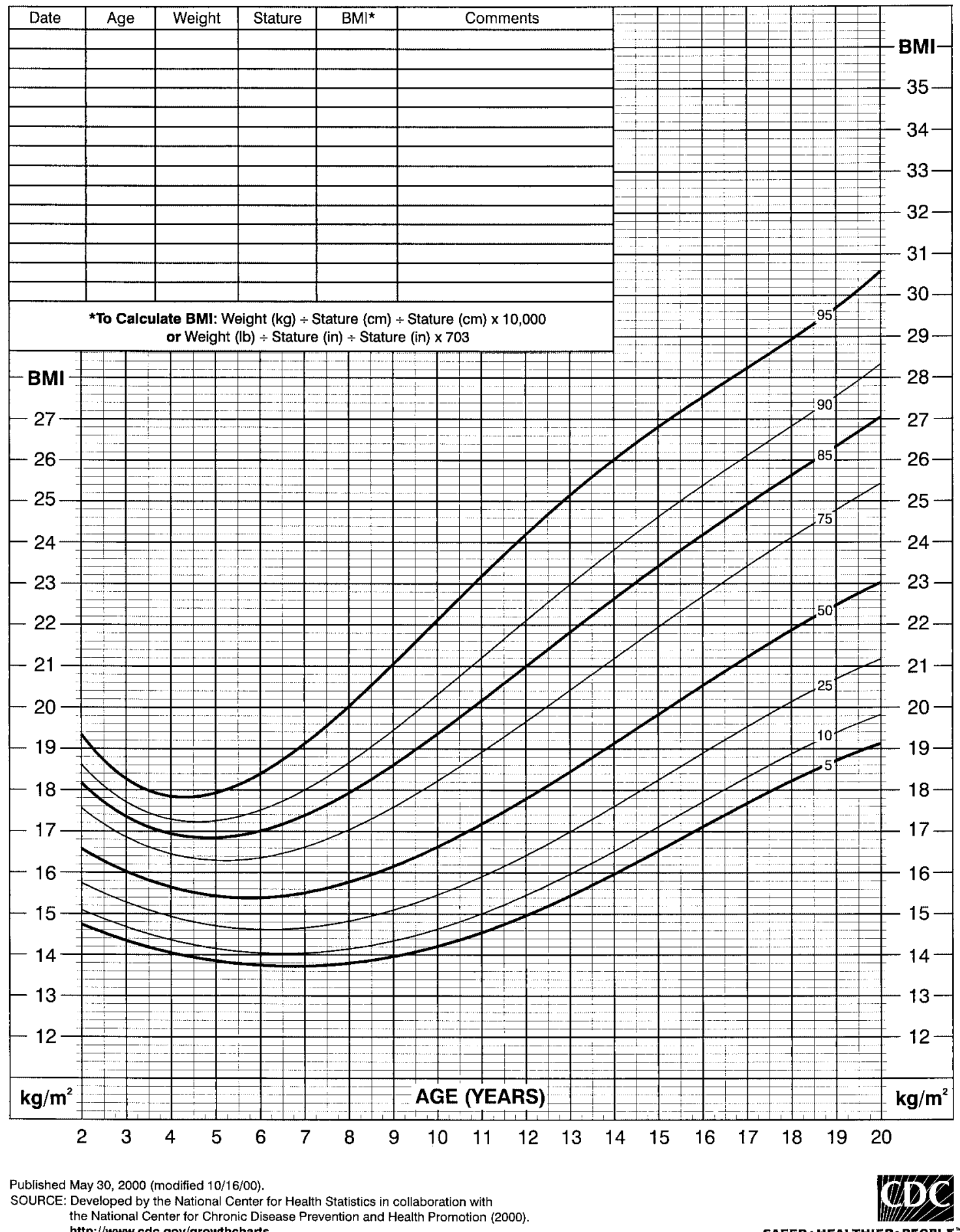
hitp://www.cdc.gov/growthcharts

Fig 7. 2000 CDC growth charts for the United States, BMI-for-age percentiles, 2 to 20 years, boys.

The disjunction between length and stature in the 1977 NCHS growth charts can also be observed by estimating the percentage of 2-year-old children in NHANES III who fall below the 5th percentile and above the 95th percentile of the weight-for-length, weight-for-stature, length-for-age, and stature-forage growth curves. If there were no disjunction, then the percentage of children who fall below the 5th percentile would be the same using the weight-forlength and weight-for-stature or length-for-age and stature-for-age curves. This also would be true for the percentage above the 95th percentile of the length and stature curves. Tables 1 and 2 show these percentages using the 1977 NCHS and 2000 CDC growth charts.

At the low end of the distribution of weight-for- 


\section{Body mass index-for-age percentiles}

RECORD \#

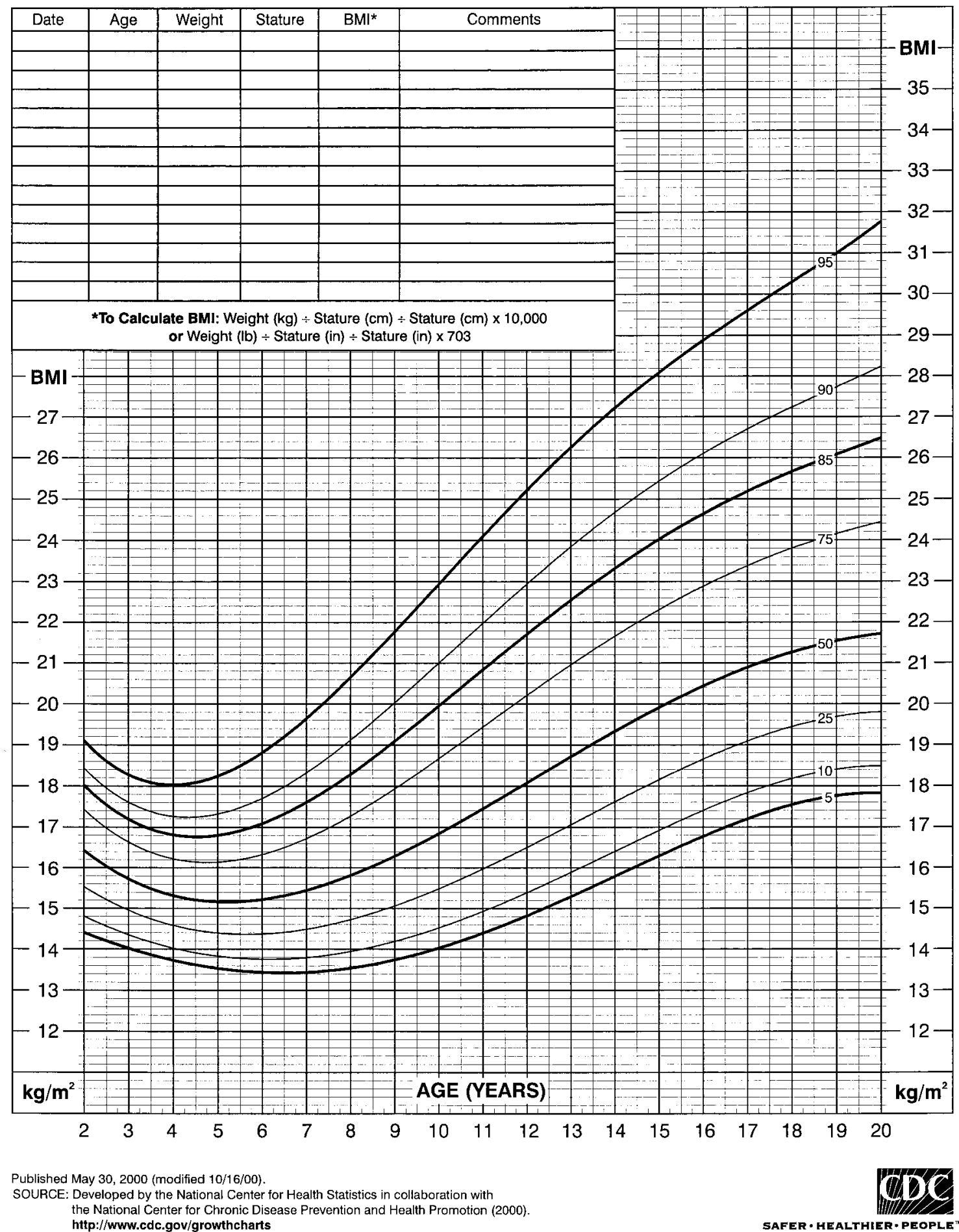

Fig 8. 2000 CDC growth charts for the United States, BMI-for-age percentiles, 2 to 20 years, girls.

length and weight-for-stature, little variation is seen. The differences in the percentage at $<5$ th percentile (underweight) between the weight-for-length and weight-for-stature curves for either the 1977 or 2000 growth charts are not large.

At the 95th percentile, more variation is seen. There are large differences in the proportion at $>95$ th percentile (overweight) between the weight- for-length and weight-for-stature charts for both boys and girls using the 1977 NCHS growth charts. For 2-year-old boys in NHANES III, approximately $9 \%$ were above the 95 th percentile using the weightfor-length chart, whereas approximately $4 \%$ of the same children were above the 95th percentile using the weight-for-stature chart. For 2-year-old girls, the rates were $20 \%$ and $4 \%$, respectively. These differ- 
Weight-for-stature percentiles: Boys

NAME

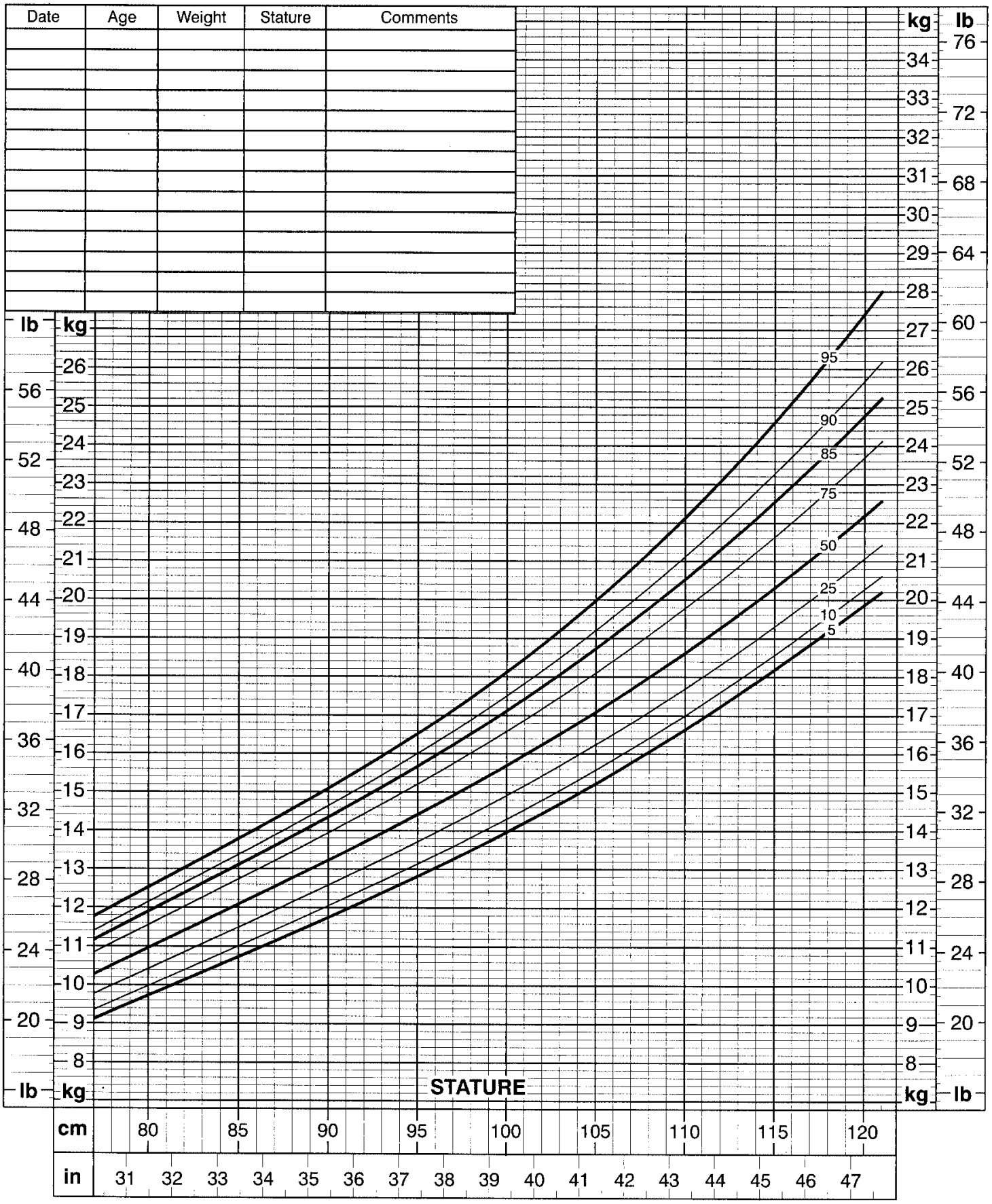

Published May 30, 2000 (modified 10/16/00).

SOURCE: Developed by the National Center for Health Statistics in collaboration with

the National Center for Chronic Disease Prevention and Health Promotion (2000)

http://www.cdc.gov/growthcharts

rape

(IIIII)

Fig 9. 2000 CDC growth charts for the United States, weight-for-stature percentiles, boys.

ences do not occur using the 2000 CDC charts. In fact, in logistic regression, ${ }^{27}$ the $2000 \mathrm{CDC}$ growth charts were more likely to predict accurately underweight or overweight based on weight-for-stature from underweight or overweight based on weight-for-length than the 1977 NCHS growth charts. Moreover, the large difference in prevalence of overweight by gen- der using the 1977 NCHS weight-for-length curve does not exist using the 2000 CDC weight-for-length curve.

Compared with weight-for-length and weight-forstature, the 1977 disjunction between length and stature is not as striking when looking at length-for-age and stature-for-age (Table 2). The only striking dif- 


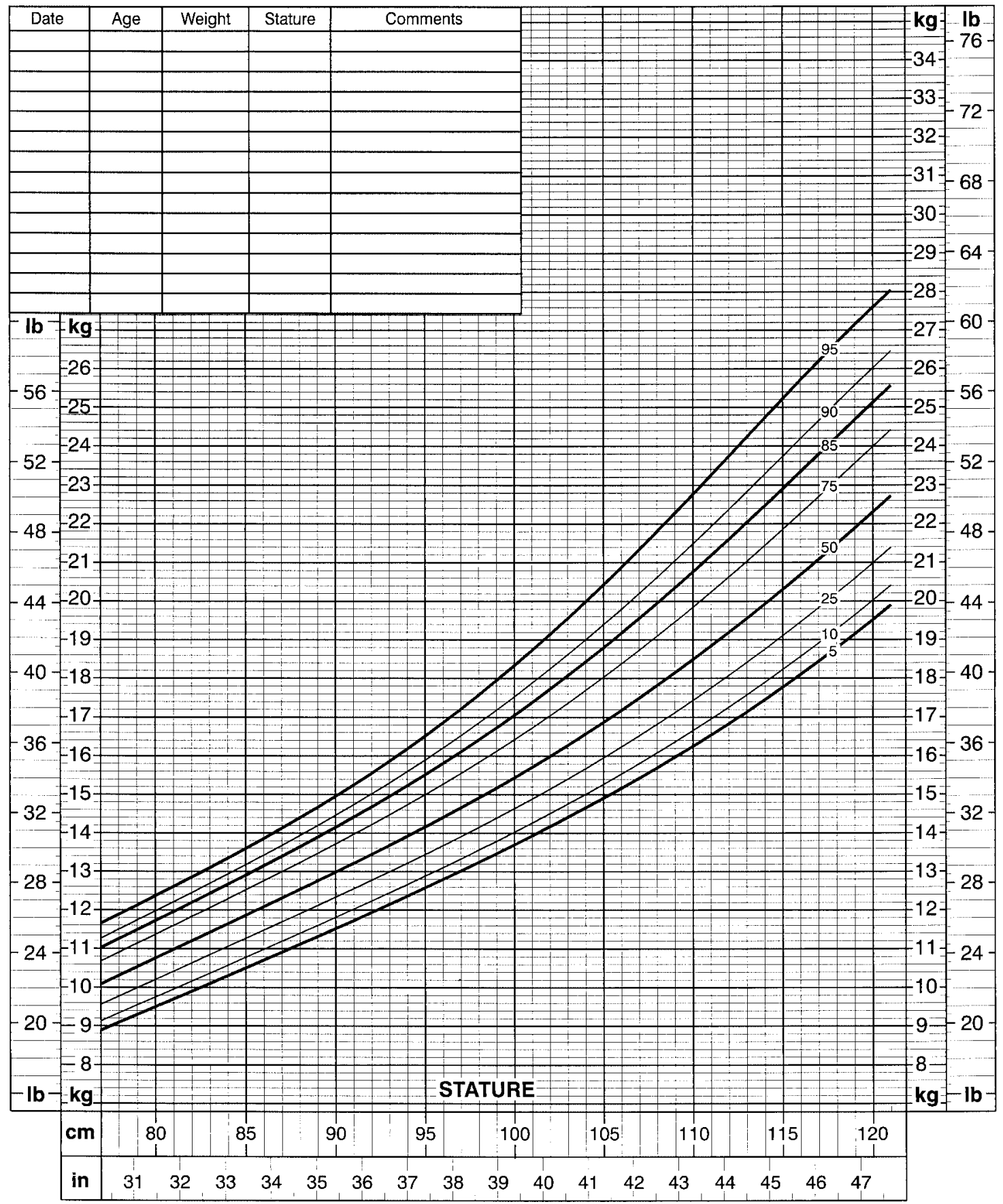

Published May 30, 2000 (modified 10/16/00).

SOURCE: Developed by the National Center for Health Statistics in collaboration with the National Center for Chronic Disease Prevention and Health Promotion (2000). http://www.cdc.gov/growthcharts

Fig 10. $2000 \mathrm{CDC}$ growth charts for the United States, weight-for-stature percentiles, girls.

ferences between length-for-age and stature-for-age in the 1977 NCHS growth charts occur at the 5th percentile, where approximately $9 \%$ of 2 -year-old boys from NHANES III are below the 5th percentile of length-for-age, whereas almost $5 \%$ of the same boys are below the 5 th percentile of stature-for-age. For 2-year-old girls, the values were almost $11 \%$ and
$6 \%$, respectively. There is virtually no difference between length-for-age and stature-for-age at the 5th percentile using the 2000 CDC growth charts. Similar to weight-for-stature and weight-for-length, logistic regression results indicate that the same result is likely to be obtained with length-for-age and staturefor-age using the 2000 CDC growth charts, whereas 


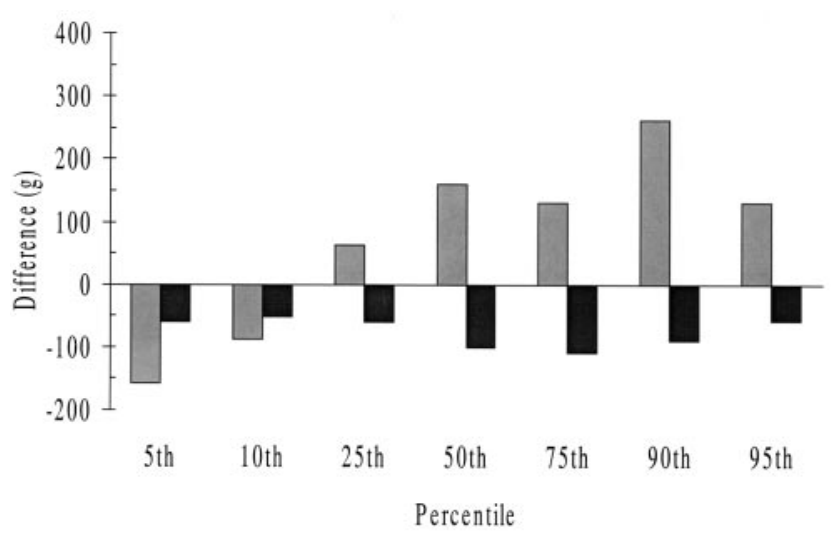

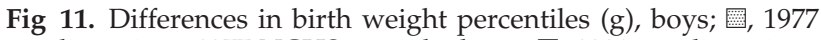
natality minus 1977 NCHS growth charts; $\mathbf{\square}, 1998$ natality minus 2000 CDC growth charts.

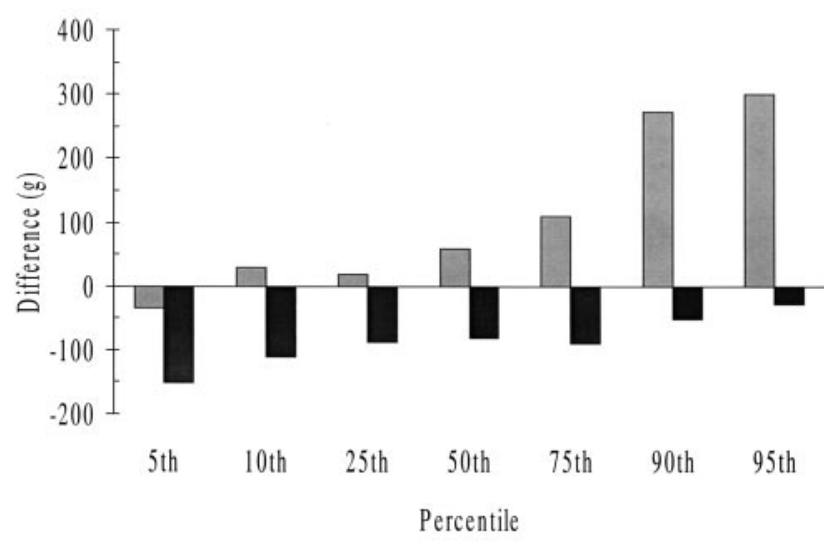

Fig 12. Differences in birth weight percentiles (g), girls; 圈, 1977 natality minus 1977 NCHS growth charts; $\mathbf{\square}, 1998$ natality minus 2000 CDC growth charts.

different results are expected between length-for-age and stature-for-age in the 1977 NCHS growth charts.

\section{One Version of Charts for Both Percentiles and $z$} Scores

As described earlier, the 2000 CDC growth charts can be used to obtain both percentiles and $z$ scores. This is a major change from the 1977 growth charts, whereby the 1977 NCHS percentiles and the normalized CDC/WHO percentiles, used to obtain $z$ scores, sometimes produced different results. The difference between the $1977 \mathrm{NCHS}$ and CDC/WHO versions was particularly evident at the 5 th and 95th percentiles, where undernutrition and overnutrition are commonly identified. For example, when the CDC/ WHO version was used to identify overweight, as $>95$ th percentile of weight-for-stature, a child was more likely to be classified as overweight than if the 1977 NCHS curves were used. Figure 15 shows that the 95th percentile of the 1977 version of weight-forstature is higher than the $\mathrm{CDC} / \mathrm{WHO}$ normalized version. This is no longer a problem with the 2000 CDC growth charts because there is only 1 version of the charts.

\section{BMI-for-Age}

The 1977 NCHS and CDC/WHO growth charts did not have curves to evaluate weight as a function of stature during adolescence. The prepubescent weight-for-stature charts stopped at age 10 for girls and 11 for boys. In the 2000 CDC version, the BMI chart is available for children and adolescents 2 to 20 years of age. BMI is recommended for screening overweight in children and adolescents. ${ }^{20,21}$

\section{DISCUSSION}

The 2000 CDC growth charts are an improvement to the 1977 NCHS and normalized CDC/WHO growth charts. These charts can be found on the Internet (www.cdc.gov/growthcharts) and in CDC's Epi Info (Centers for Disease Control and Prevention, Atlanta, GA) software program, where both exact percentiles and $z$ scores can be calculated. The Fels data used in the 1977 version have been replaced with national data, and there is only 1 version of the growth charts for calculating percentiles and $z$ scores. Moreover, BMI-for-age is now available for ages 2 to 20 years. The clinical version of the charts presented here provides users with metric scaled charts that contain data entry boxes.

Unlike the 1977 NCHS growth charts, the 2000 CDC growth charts are based on the current mix of breastfed and formula-fed infants in the United States. Breastfed infants may grow differently from formula-fed infants in the first year of life, ${ }^{28-30}$ and current feeding recommendations advise that infants be exclusively breastfed in the early months and that partial breastfeeding continue for at least 1 year. ${ }^{31,32}$ Dewey et $\mathrm{al}^{33}$ showed that the 2000 CDC weight curve still does not correspond exactly to the weight of infants who are breastfed for at least 12 months. The mean weight of the breastfed infants was higher than the 50th percentile of the 2000 CDC growth charts before 6 months of age but below the 50th percentile after 6 months of age. Mean length, however, was very close to the 2000 CDC 50th percentile. Adequate national data do not exist for exclusively or predominantly breastfed infants, so creation of growth charts for breastfed infants is not possible. Nonetheless, the assessment of growth in breastfed infants on the 2000 CDC growth charts can be made. Clinicians may wish to take into account type of feeding when making the assessment. The WHO is currently developing growth charts for preschoolage children based on prescriptive criteria for feeding. ${ }^{34}$ Unlike the 1977 NCHS or 2000 CDC curves, the new WHO growth charts will be based on breastfed infants and will contain data from study centers in 6 countries.

There is no disjunction between weight-for-length and weight-for-stature or length-for-age and staturefor-age in the 2000 CDC growth charts. In this version, differences reflect the biological differences between recumbent length and stature. Although an individual child may be above the 95th percentile of weight-for-length but not above the 95th percentile of weight-for-stature using the 1977 curves, similar findings are much less likely using the 2000 CDC curves. Dibley et $\mathrm{al}^{2,3}$ found a disparity similar to that found in this analysis when they compared data from 2-year-old children in NHANES II with the $\mathrm{CDC} / \mathrm{WHO}$ growth charts. Any differences in prev- 

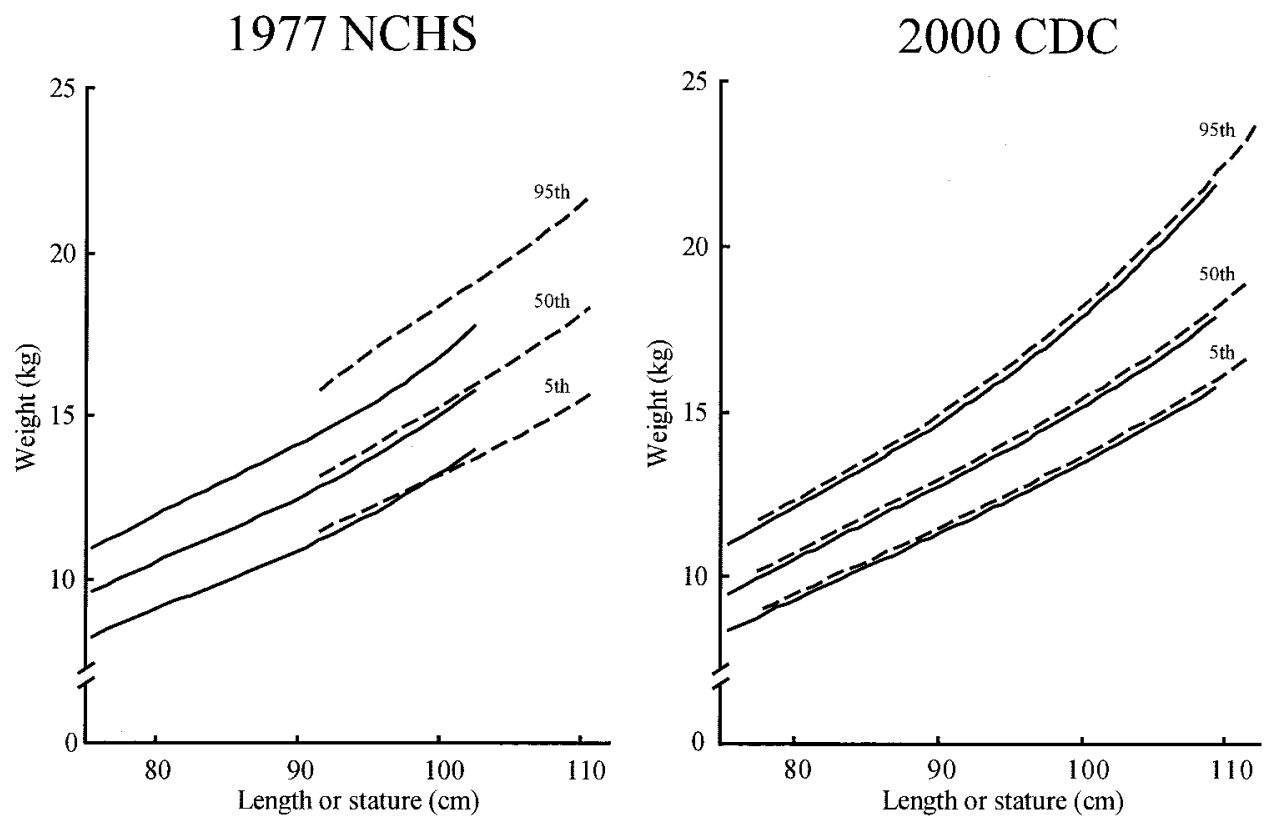

Fig 13. 1977 NCHS and 2000 CDC growth charts for girls: 5th, 50th, and 95th percentiles of weight-for-length (一) and weight-for-stature $(---)$.
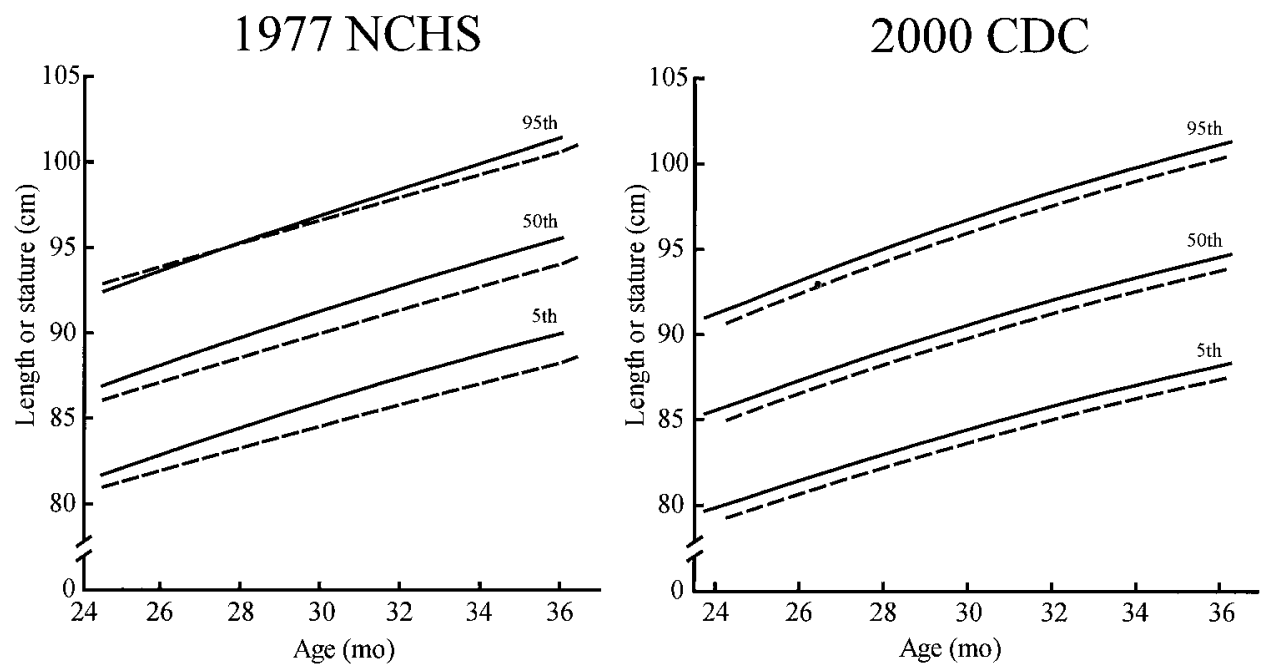

Fig 14. 1977 NCHS and 2000 CDC growth charts for girls: 5th, 50th. and 95th percentiles of length-for-age (-) and stature-for-age (---).

TABLE 1. Percentage (SE) at $<5$ th Percentile and $>95$ th Percentile of Weight-for-Length and Weight-for-Stature, 1977 NCHS Growth Charts and 2000 CDC Growth Charts, 2-Year-Old Children by Gender, NHANES III, 1988 to 1994

\begin{tabular}{lccccc}
\hline & $n$ & $\begin{array}{c}\text { Weight-for- } \\
\text { Length }<5 \text { th } \\
\text { Percentile }\end{array}$ & $\begin{array}{c}\text { Weight-for- } \\
\text { Stature }<5 \text { th } \\
\text { Percentile }\end{array}$ & $\begin{array}{c}\text { Weight-for- } \\
\text { Length }>95 \text { th } \\
\text { Percentile }\end{array}$ & $\begin{array}{c}\text { Weight-for- } \\
\text { Stature }>95 \text { th } \\
\text { Percentile }\end{array}$ \\
\hline Boys & & & & & \\
1977 NCHS & 342 & $0.39(0.23)$ & $1.28(0.59)$ & $8.66(1.97)$ & $3.98(1.28)$ \\
2000 CDC & 342 & $1.69(0.61)$ & $1.84(0.64)$ & $5.23(1.43)$ & $6.26(1.66)$ \\
Girls & 269 & $1.35(0.84)$ & $1.58(0.86)$ & $19.87(3.41)$ & $4.13(1.30)$ \\
1977 NCHS & 269 & $1.90(0.89)$ & $2.13(0.91)$ & $7.17(1.71)$ & $8.05(1.22)$ \\
2000 CDC & & & & & \\
\hline
\end{tabular}

SE indicates standard error.

alence by gender using the 2000 CDC length and stature curves is likely to be attributable to biological differences between length and stature.

The 2000 CDC growth charts are an improvement to the 1977 NCHS growth charts. They are based on samples of children from 2 months to 20 years of age and include breastfed and formula-fed infants. The weight curves include national birth weight data, and the length curves include birth length data from 2 states. A disjunction as a result of different data sources did not occur. In addition, the overlapping portions of the curves for recumbent length and stat- 
TABLE 2. Percentage (SE) at $<5$ th Percentile and $>95$ th Percentile of Length-for-Age and Stature-for-Age, 1977 NCHS Growth Charts and 2000 CDC Growth Charts, 2-Year-Old Children by Gender, NHANES III, 1988 to 1994

\begin{tabular}{cccccc}
\hline & $n$ & $\begin{array}{c}\text { Length-for- } \\
\text { Age }<5 \text { th } \\
\text { Percentile }\end{array}$ & $\begin{array}{c}\text { Stature-for- } \\
\text { Age }<5 \text { th } \\
\text { Percentile }\end{array}$ & $\begin{array}{c}\text { Length-for- } \\
\text { Age }>95 \text { th } \\
\text { Percentile }\end{array}$ & $\begin{array}{c}\text { Stature-for- } \\
\text { Age }>95 \text { th } \\
\text { Percentile }\end{array}$ \\
\hline Boys & & & & \\
1977 NCHS & 567 & $9.30(1.66)$ & $4.92(0.77)$ & $2.50(0.98)$ & $1.99(0.83)$ \\
2000 CDC & 567 & $4.64(0.98)$ & $4.00(0.74)$ & $3.56(1.10)$ & $2.43(0.93)$ \\
Girls & & & & & $2.11(0.82)$ \\
1977 NCHS & 548 & $10.67(2.13)$ & $5.98(1.16)$ & $4.43(1.08)$ & $4.16(1.28)$ \\
2000 CDC & 548 & $3.96(0.93)$ & $4.84(1.13)$ & $4.77(1.11)$ & \\
\hline
\end{tabular}

SE indicates standard error.

Fig 15. 1977 NCHS (---) and CDC/ WHO normalized (-) weight-for-stature growth charts for girls, 95th percentiles.

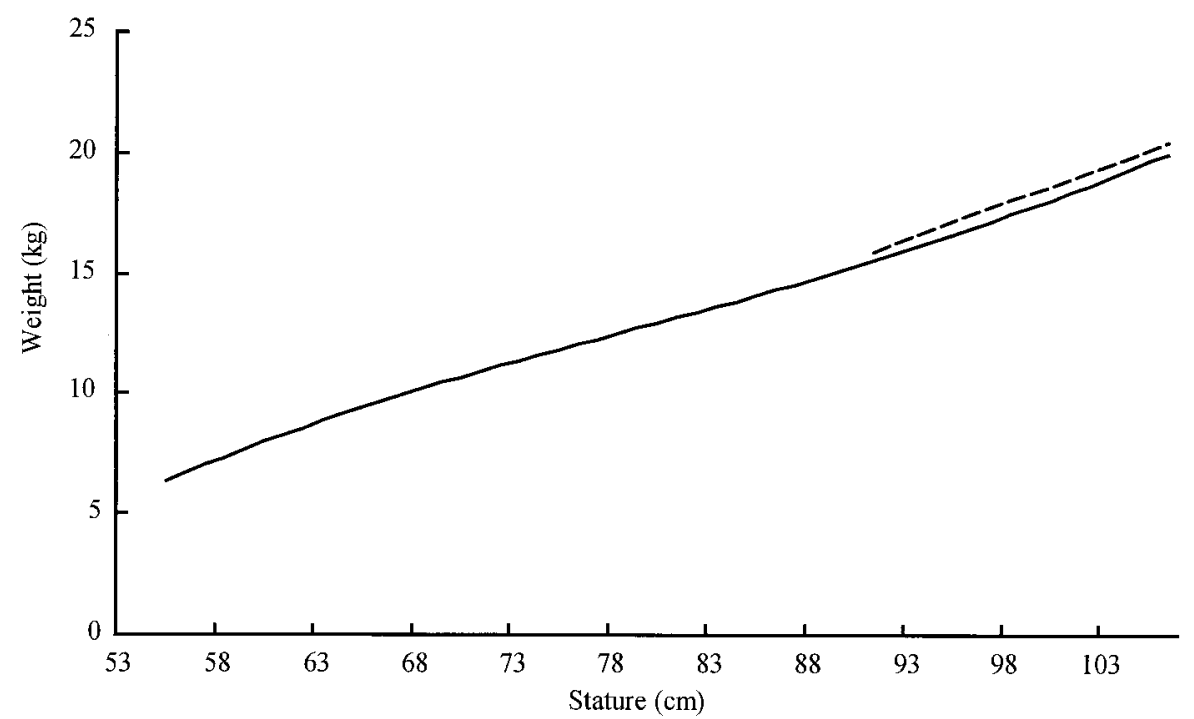

ure from 24 to 36 months of age were made parallel to each other during the smoothing process. The minimized disjunctions are attributable to inherent differences between length and stature measures.

The 2000 CDC growth charts are recommended for use in the United States. Pediatric clinics should make the transition from the 1977 NCHS to the 2000 CDC charts for routine monitoring of growth in infants, children, and adolescents.

\section{ACKNOWLEDGMENTS}

We thank Catherine Duran and Kenneth Schoendorf, MD, for providing the national distributions of birth weights.

\section{REFERENCES}

1. Hamill PV, Drizd TA, Johnson CL, Reed RB, Roche AF, Moore WM. Physical growth: National Center for Health Statistics percentiles. Am J Clin Nutr. 1979;32:607-629

2. Dibley MJ, Goldsby JB, Staehling NW, Trowbridge FL. Development of normalized curves for the international growth reference: historical and technical considerations. Am J Clin Nutr. 1987;46:736-748

3. Dibley MJ, Staehling N, Nieburg P, Trowbridge FL. Interpretation of Z-score anthropometric indicators derived from the international growth reference. Am J Clin Nutr. 1987;46:749-762

4. World Health Organization. A Growth Chart for International Use in Maternal and Child Health Care: Guidelines for Primary Health Care Personnel. Geneva, Switzerland: WHO; 1978

5. Sullivan K, Trowbridge F, Gorstein J, Pradilla A. Growth references. Lancet. 1991;337:1420-1421

6. Graitcer PL, Gentry EM. Measuring children: one reference for all. Lancet. 1981;2:297-299

7. Kuczmarski RJ, Ogden CL, Grummer-Strawn LM, et al. CDC growth charts: United States. Adv Data. 2000;314:1-27

8. Roche AF. Growth, Maturation and Body Composition: The Fels Longitudinal
Study 1929-1991. Cambridge, UK: Cambridge University Press; 1992

9. Roche AF. Executive Summary of the Growth Chart Workshop, December 1992. Hyattsville, MD: National Center for Health Statistics; 1994

10. de Onis M, Yip R. The WHO growth chart: historical considerations and current scientific issues. Bibl Nutr Dieta. 1996;53:74-89

11. Cole TJ. A critique of the NCHS weight for height standard. Hum Biol. 1985;57:183-196

12. Hamill PV, Drizd TA, Johnson CL, Reed RB, Roche AF. NCHS growth curves for children birth-18 years United States. Vital Health Stat 11. 1977;165:1-74

13. Plan and operation of the Third National Health and Nutrition Examination Survey, 1988-94. Vital Health Stat 1. 1994;32:1-407

14. Guo SS, Roche AF, Chumlea WC, Casey PH, Moore WM. Growth in weight, recumbent length, and head circumference for preterm lowbirthweight infants during the first three years of life using gestationadjusted ages. Early Hum Dev. 1997;47:305-325

15. Guo SS, Wholihan K, Roche AF, Chumlea WC, Casey PH. Weight-forlength reference data for preterm, low birth weight infants. Arch Pediatr Adolesc Med. 1996;150:964-970

16. Casey PH, Kraemer HC, Bernbaum J, et al. Growth patterns of low birth weight preterm infants: a longitudinal analysis of a large varied sample. J Pediatr. 1990;117:298-307

17. Casey PH, Kraemer HC, Bernbaum J, Yogman MW, Sells JC. Growth status and growth rates of a varied sample of low birth weight, preterm infants: a longitudinal cohort from birth to three years of age. J Pediatr. 1991;119:599-605

18. Brandt I. Growth dynamics of low birth weight infants with emphasis on the perinatal period. In: Falkner F, Tanner JM, eds. Human Growth: 2. Postnatal Growth. New York, NY: Plenum Press; 1978:557-617

19. Troiano RP, Flegal KM, Kuczmarski RJ, Campbell SM, Johnson CL. Overweight prevalence and trends for children and adolescents: the National Health and Nutrition Examination Surveys, 1963 to 1991. Arch Pediatr Adolesc Med. 1995;149:1085-1091

20. Himes JH, Dietz WH. Guidelines for overweight in adolescent preventive services: recommendations from an expert committee. Am J Clin Nutr. 1994;59:307-316

21. Barlow SE, Dietz WH. Obesity evaluation and treatment: Expert Com- 
mittee recommendations. The Maternal and Child Health Bureau, Health Resources and Services Administration and the Department of Health and Human Services. Pediatrics. 1998;102(3). Available at: http://www.pediatrics.org/cgi/content/full/102/3/e29

22. Cole TJ. The LMS method for constructing normalized growth standards. Eur J Clin Nutr. 1990;44:45-60

23. Mei Z, Yip R, Grummer-Strawn LM, Trowbridge FL. Development of a research child growth reference and its comparison with the current international growth reference. Arch Pediatr Adolesc Med. 1998;152: 471-479

24. Kuczmarski RJ, Ogden CL, Guo S, et al. 2000 CDC Growth Charts for the United States. Hyattsville, MD: NCHS; In press

25. Population Estimates Program. Washington, DC: US Census Bureau; 1990

26. National Center for Health Statistics. Health, United States, 1998 With Socioeconomic Status and Health Chartbook. Hyattsville, MD: National Center for Health Statistics; 1998

27. Hosmer DW, Lemeshow S. Applied Logistic Regression. New York, NY: John Wiley \& Sons; 1989
28. Dewey KG, Heinig MJ, Nommsen LA, Peerson JM, Lonnerdal B. Growth of breast-fed and formula-fed infants from 0 to 18 months: the DARLING Study. Pediatrics. 1992;89:1035-1041

29. Dewey KG, Peerson JM, Brown KH, et al. Growth of breast-fed infants deviates from current reference data: a pooled analysis of US, Canadian, and European data sets. Pediatrics. 1995;96:495-503

30. WHO Working Group on the Growth Reference Protocol, WHO Task Force on Methods for the Natural Regulation of Fertility. Growth patterns of breastfed infants in seven countries. Acta Paediatr. 2000;89:215-222

31. American Academy of Pediatrics. Breastfeeding and the use of human milk (RE9729). Pediatrics. 1997;100:1035-1039

32. American Academy of Pediatrics, Committee on Nutrition. Pediatric Nutrition Handbook. 4th Ed. Elk Grove Village, IL: American Academy of Pediatrics; 1998

33. Dewey KG. Nutrition, growth and complementary feeding of the breastfed infant. Pediatr Clin North Am. 2001;48:87-104

34. WHO Working Group on the Growth Reference Protocol. A Growth Curve for the 21st Century: The WHO Multicentre Growth Reference Study. Geneva, Switzerland: WHO; 1998

\section{PARENTS SEE BENEFITS OF VIDEOCONFERENCES}

“... A small number of parents are beginning to use videoconferencing as a bridge across all the kinds of parent-child separations work can impose, from travel and temporary transfers to postdivorce relocations. In encounters unnervingly akin to the old Jetsons cartoons, these families are 'meeting' on camera in exchanges that can be rich in emotion. . Experts agree videoconferencing can be a valuable parenting tool. 'It's not an experience of intimacy of the same kind as when you're there, cuddling or getting down on the floor to play,' says Stanley Greenspan, a clinical professor at George Washington University Medical School, Washington, DC... With older children, videoconferencing can provide parents more information than they'd get by phone or e-mail. . It's also important to note that this is largely uncharted turf with regard to the development of very young children. . Parent-child videoconferencing seems likely to grow. As the technology improves, a new generation of parents-to whom this Jetsonesque technology isn't so fantastic - may embrace it to help cope with their heaviest years of workfamily stress."

Noted by JFL, MD 